ORIGINAL ARTICLE

\title{
ON THE RECOVERY OF TEMPORAL VARIATIONS OF GEOID HEIGHTS DETERMINED WITH THE USE OF GGMS BASED ON SST-HL DATA FROM NON-DEDICATED GRAVITY SATELLITE MISSIONS
}

\author{
Walyeldeen Godah ${ }^{1}$ - ORCID 0000-0002-5616-0770 \\ Malgorzata Szelachowska' - ORCID 0000-0002-6421-7589 \\ Jan Krynski ${ }^{1}$ - ORCID 0000-0003-0695-9821 \\ ${ }^{1}$ Institute of Geodesy and Cartography Centre of Geodesy and Geodynamics, \\ E-mail: walyeldeen.godah@igik.edu.pl \\ E-mail: malgorzata.szelachowska@igik.edu.pl \\ E-mail: jan.krynski@igik.edu.pl
}

Received in $26^{\text {th }}$ October 2018

Accepted in $15^{\text {th }}$ May 2019

\section{Abstract:}

Over 15 years the Gravity Recovery and Climate Experiment (GRACE) had considerably contributed to the determination of temporal variations of geoid heights. In May 2018, GRACE Follow-On (GRACE-FO) was launched. The aim of this contribution is to assess the suitability of data from non-dedicated gravity satellite missions (N-DGSMs) for the determination of temporal variations of geoid heights and bridging the gap between GRACE and GRACE-FO. The Amazon basin and the area of Poland were chosen as study areas. Monthly Global Geopotential Models (GGMs) developed using N-DGSMs data were utilized to determine temporal variations of geoid heights over the chosen study areas. Then, the obtained temporal variations of geoid heights were evaluated using ITSG-GRACE2016 GGMs. Time series of geoid height variations determined from GGMs of some N-DGSMs were smoothed using a moving average. The main findings reveal that for areas characterized with strong mass transport, e.g. the Amazon basin, correlation coefficients between smoothed temporal variations of geoid heights from GGMs of some NDGSMs and temporal variations of geoid heights from the ITSG-GRACE2016 GGMs reach the level of 0.6. For areas with a weak mass transport signal as for Poland, N-DGSMs-based GGMs investigated seem unsuitable for determining temporal variations of geoid heights.

Keywords: geoid height; GGM, GRACE/GRACE-FO; non-dedicated gravity satellite missions. 


\section{Introduction}

A precise geoid is essentially needed for the realization of the vertical reference system. It serves as a reference surface for the transformation between the geometrical ellipsoidal height obtained from Global Navigation Satellite System (GNSS) measurements and gravity-based heights, e.g. orthometric and normal heights, determined with the use of spirit levelling (cf. Torge and Müller 2012). It is also required in many Earth's science disciplines. For example, a precise geoid is highly important in geophysics for understanding mass distribution in the Earth interior. In oceanography, the geoid is needed to study the sea-surface topography and its dynamic processes, as well as to study the ocean circulation, which is responsible for a large part of the global heat and energy transport, and thus plays a crucial role in the climate regulation (ibid). Recent studies, e.g. Rangelova (2007), Rangelova and Sideris (2008), Rangelova et al. (2010), Krynski et al. (2014) and Godah et al. (2017, 2018), reveled the importance of temporal variations of geoid heights for high accuracy regional geoid modelling that has been considered as one of the activities of the Joint Study Group 0.15 (JSG 0.15) of the Commission 2 - Gravity Field of the International Association of Geodesy (IAG) (see Drewes et al. 2016).

Since late 1950s, the analysis of artificial satellite orbits revealed valuable results concerning geoid modelling (e.g. Veis 1960). In the early $21^{\text {st }}$ century, due to the launch of three dedicated gravity satellite missions, i.e. the CHAllenging Mini-Satellite Payload (CHAMP; Reigber et al. 2002), Gravity Recovery and Climate Experiment (GRACE; Tapley et al. 2004) and Gravity field and steady state Ocean Circulation Explorer (GOCE; Floberghagen et al. 2011), a significant progress concerning geoid modelling has been achieved. Among those missions, the GRACE satellite mission, launched in April 2002, with its K-band ranging system measurements, provided monthly, weekly and daily data to determine temporal variations of geoid heights with an unprecedented accuracy as well as spatial and temporal resolutions. This mission was operated three times longer than its initial planned duration. In October 2017, GRACE satellites ran out of fuel, and the mission was terminated. The results of this mission, however, have emphasized the need for continuously operating GRACE-type missions. On 22 May 2018, the GRACE Follow-On (GRACE-FO) satellite mission was launched (see GRACE-FO 2018). Bridging the gap between GRACE and GRACE-FO satellite missions to monitor mass transport in the Earth system has been considered an important task of the Earth science-related disciplines. Many investigations on the determination of mass transport within the Earth system using different data to bridge that gap have recently been conducted. For example, Zehentner et al. (2014) demonstrated the usefulness of non-dedicated gravity satellite missions (N-DGSMs) for estimating temporal variations of equivalent water thickness on a large scale; Bezděk et al. (2016), de Encarnação et al. (2016), Dahle et al. (2017) and Jäggi et al. (2018) investigated the use of Swarm satellite mission orbits data for the determination of the Earth gravity field; Lück et al. (2018) estimated the ocean mass changes using Swarm satellite mission orbits data. So far, bridging the gap between GRACE and GRACE-FO is remaining one of the main issues that should be solved by the GRACE/GRACE-FO science team (cf. the latest GRACE/GRACE-FO Science Team Meeting; GSTM 2018).

The main objective of this contribution is to investigate the suitability of N-DGSMs for bridging the gap between GRACE and GRACE Follow-On satellite missions. It is particularly aimed at the assessment of recovering temporal variations of geoid heights for that gap using GGMs 
developed on the basis of SST-hI (Satellite-to-Satellite Tracking in the high-low mode) data from N-DGSMs.

\section{Data used}

Monthly GGMs obtained on the basis of SST-hl data from eleven satellites of N-DGSMs: Jason-2, Jason-3, MetOp-A, MetOp-B, Sentinel-3A, Kompsat-5, Swarm-3, TanDEM-X, TerraSAR-X, Swarm1 , and Swarm-2, were used in this investigation. Those GGMs were developed within the framework of the TVGOGO (Time Variable Gravity Observed by GPS derived Orbit positions; TVGOGO 2018) project conducted at the Graz University of Technology. The procedure implemented to determine time series of monthly gravity field models from kinematic orbits of satellites of those N-DGSMs is described in Zehentner and Mayer-Gürr (2016). The altitudes of satellites of those $\mathrm{N}$-DGSMs are given in Table 1.

Table 1: Altitudes of satellites of non-dedicated gravity satellite missions

\begin{tabular}{l|c|l}
\hline N-DGSM & Altitude $[\mathrm{km}]$ & Reference \\
\hline Jason-2 & 1336 & Neeck and Vaze 2008 \\
\hline Jason-3 & 1336 & Jason-3 2018 \\
\hline MetOp-A & 820 & METOP 2018 \\
\hline MetOp-B & 820 & METOP 2018 \\
\hline Sentinel-3A & 814 & Sentinel 2018 \\
\hline Kompsat-5 & 550 & Sang-Ryool 2010 \\
\hline Swarm-3 & 530 & Friis-Christensen et al. 2008 \\
\hline TanDEM-X & 515 & DLR 2009 \\
\hline TerraSAR-X & 515 & Rothacher et al. 2007 \\
\hline Swarm-1 & 450 & Friis-Christensen et al. 2008 \\
\hline Swarm-2 & 450 & Friis-Christensen et al. 2008
\end{tabular}

In addition to GGMs based on data from N-DGSMs, monthly release 5 (RL05) GRACE-based GGMs developed by the CSR (Centre for Space Research; cf. Bettadpur 2012) and ITSGGRACE2016 GGMs from the Institute of Geodesy of the Graz University of Technology (MayerGürr et al. 2016), were utilized for the validation purposes.

\section{Method}

The Amazon basin and the area of Poland were selected as study areas. These areas are characterized with different strength of temporal variations of geoid heights signal. The Amazon basin was divided in this research into 48 subareas of $3^{\circ} \times 3^{\circ}$, while the area of Poland - into four subareas of $3^{0} \times 5^{0}$ (cf. Godah et al. 2017; 2018) (Fig. 1). 


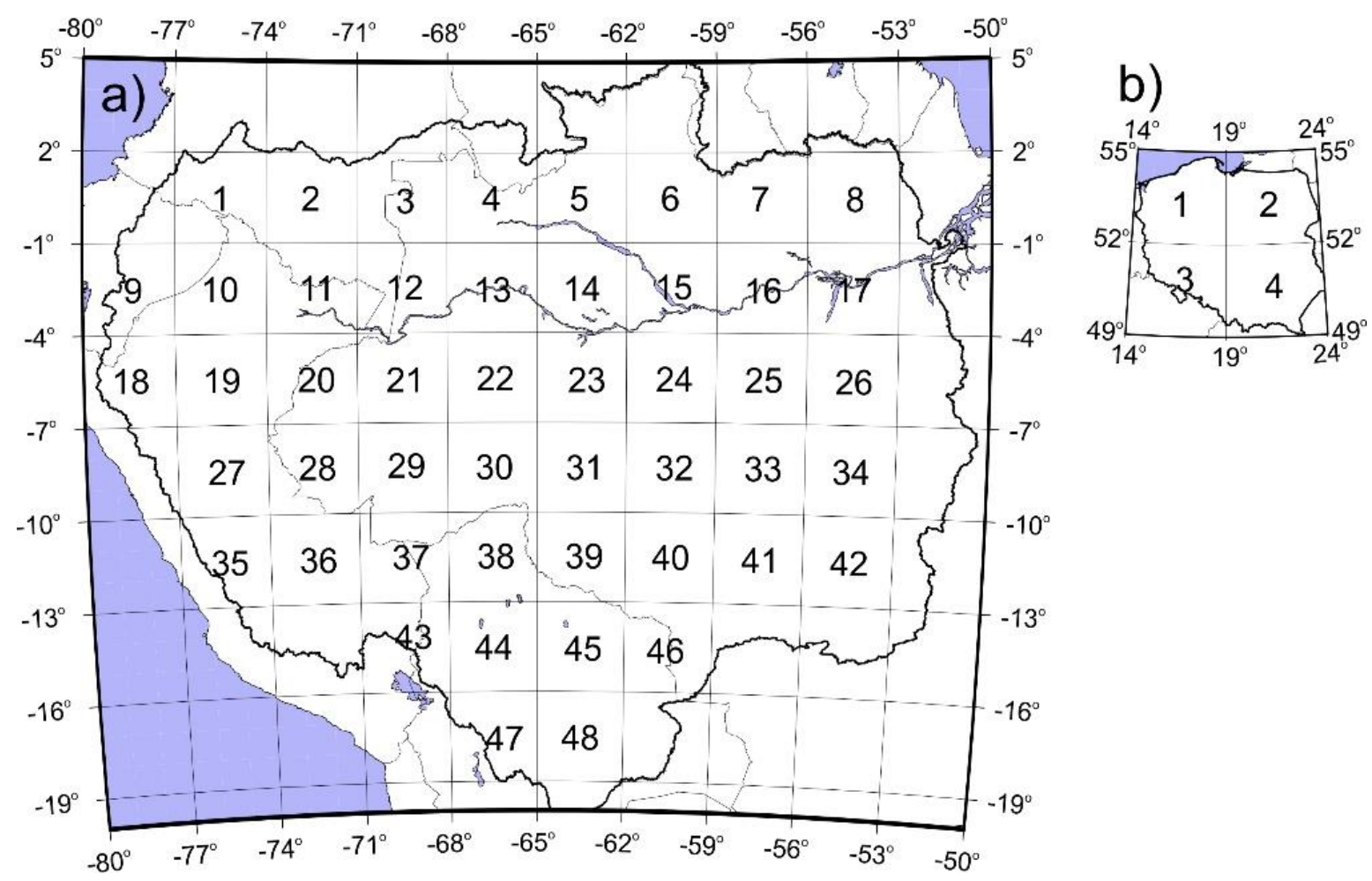

Figure 1: Study areas and their subareas (a) the Amazon basin, and (b) the area of Poland.

Temporal variations of geoid heights $\Delta N$ were determined at the centre points of each subarea (see Figure 1) using primarily the IGiK-TVGMF (Godah 2019), a MATLAB package developed at the Institute of Geodesy and Cartography, Warsaw, Poland, for computation and analysis of temporal variations of gravity/mass functionals from GRACE-based GGMs as well as the modified version of this package with N-DGSM-based GGMs as an input data as follows:

$$
\Delta N_{(r, \varphi, \lambda)}=\frac{G M}{r \gamma} \sum_{n=2}^{N_{\max }}\left(\frac{R}{r}\right)^{n} \sum_{m=0}^{n} \bar{P}_{n m}(\sin \varphi)\left(w_{n} \Delta C_{n m} \cos m \lambda+w_{n} \Delta S_{n m} \sin m \lambda\right)
$$

where $r, \varphi, \lambda$ are spherical geocentric coordinates of the computation point, $R$ is the reference radius of the Earth, $G M$ is the product of the Newtonian gravitational constant $G$ and the Earth's mass $M, \bar{P}_{n m}$ are the fully normalized Legendre functions, $\gamma$ denotes the normal gravity, $\Delta C_{n m}$ and $\Delta S_{n m}$ present the differences between spherical harmonic coefficients of GRACE-based GGMs or N-DGSM-based GGMs and the corresponding ones from the reference model, and $w_{n}$ denotes the Gaussian filter (e.g. Wahr et al. 1998) used to reduce the noise in GGMs investigated.

The Gaussian filter of the radius of $500 \mathrm{~km}$ was used. Temporal variations of geoid heights were computed from GGMs truncated at d/o (degree/order) of 60 that corresponded to the spatial resolution of the subareas used in this investigation (see Fig. 1). The second d/o spherical 
harmonic coefficients, i.e. $C_{20}$, for all GGMs investigated were compensated with the corresponding ones obtained from satellite laser ranging data (Cheng et al. 2013). The Earth Gravitational Model 2008 (EGM2008; Pavlis et al. 2012) and the World Geodetic System 1984 (WGS84) were used as a reference model and reference system, respectively.

Time series of monthly geoid height variations obtained at each subarea were centered to zero by subtracting their bias values as follows:

$$
\Delta N^{\text {centered }}=\Delta N-\Delta N_{\text {average }}
$$

where $\Delta N_{\text {average }}$ is the average value obtained from the time series of $\Delta N$. Then, mean variations of geoid heights over study areas, i.e. over the Amazon basin and the area of Poland, for each month were obtained as follows:

$$
\left.\Delta N^{\text {mean }}=\sum_{j=1}^{k} \frac{\Delta N_{j}^{\text {centerd }}}{k} \quad \begin{array}{l}
\text { for the Amazon basin, } k=48 \\
\text { for the area of Poland, } k=4
\end{array}\right\}
$$

where $j$ denotes the number of subarea.

Monthly mean of temporal variations of geoid height $\Delta N^{\text {(SST-hl) }}$ determined from N-DGSM-based GGMs were evaluated using the corresponding ones computed from suitable GGMs developed with the use of GRACE satellite mission data. The ITSG-GRACE2016 GGMs were chosen for the evaluation since time series of those GGMs are the longest and the most updated among GRACE-based GGMs so far developed along the period from April 2002 to June 2017.

Firstly, the suitability of ITSG-GRACE2016 GGMs for the evaluation of $\Delta N^{(\text {SST-hl) }}$ over the chosen study areas was assessed using the official GRACE Science Data System monthly gravity solutions, i.e. CSR RL05 GGMs. Monthly mean of temporal variations of geoid heights $\Delta N^{(\mathrm{ITSG})}$ calculated from ITSG-GRACE2016 GGMs and $\Delta N^{(\mathrm{CSR})}$ from CSR RL05 GGMs were obtained using Eqs. (1-3). Then, the differences between $\Delta N^{(\mathrm{ITSG})}$ and $\Delta N^{(\mathrm{CSR})}$ were calculated as follows:

$$
\delta \Delta N^{(\mathrm{CSR}-\mathrm{ITSG})}=\Delta N^{(\mathrm{CSR})}-\Delta N^{(\mathrm{ITSG})}
$$

Secondly, $\Delta N^{\text {(SST-hl) }}$ were determined over the investigated areas using Eqs. (1-3). Thereafter, they were evaluated using the corresponding ones obtained from ITSG-GRACE2016 GGMs, i.e. $\Delta N^{(\mathrm{ITSG})}$, and the differences

$$
\delta \Delta N^{(\mathrm{ITSG}-\mathrm{SST})}=\Delta N^{(\mathrm{ITSG})}-\Delta N^{(\mathrm{SST}-\mathrm{hl})}
$$


were calculated.

In the final step, time series of $\Delta N^{(\text {SST-hl) }}$ for some N-DGSMs were smoothed using a moving average of 3 months window size as follows:

$$
\Delta N_{i}^{\text {SST-hl smoothed }}=\frac{\Delta N_{i-1}^{\text {mean }}+\Delta N_{i}^{\text {mean }}+\Delta N_{i+1}^{\text {mean }}}{3}
$$

where $i$ denotes the month. The smoothed time series of geoid height variations were also evaluated using $\Delta N^{(\mathrm{ITSG})}$. The differences between $\Delta N^{(\mathrm{ITSG})}$ and $\Delta N^{\text {(SST-hl smoothed), }}$

$$
\delta \Delta N^{(\text {smoothed })}=\Delta N^{(\text {ITSG) }}-\Delta N^{(\text {SST-hl smoothed })}
$$

were determined.

The correlation coefficient (Corr. coef.) and the standard deviation of the differences (Std. dev.) between a pair of $\Delta N^{\text {mean }}$ time series, e.g. $\Delta N^{\text {mean(1) }}$ and $\Delta N^{\text {mean(2) }}$, were obtained as follows:

$$
\text { Corr. coef. }=\frac{\sum_{v=1}^{q}\left(\Delta N_{v}^{\operatorname{mean}(1)}-\overline{\Delta N^{\operatorname{mean}(1)}}\right)\left(\Delta N_{v}^{\operatorname{mean}(2)}-\overline{\Delta N^{\operatorname{mean}(2)}}\right)}{\sqrt{\sum_{v=1}^{q}\left(\Delta N_{v}^{\operatorname{mean}(1)}-\overline{\Delta N^{\operatorname{mean}(1)}}\right)^{2} \sum_{v}^{q}\left(\Delta N_{v}^{\operatorname{mean}(2)}-\overline{\Delta N^{\text {mean(2) }}}\right)^{2}}}
$$

Std. dev. $=\sqrt{\frac{\sum_{v=1}^{q}\left(\left(\Delta N_{v}^{\text {mean }(1)}-\Delta N_{v}^{\text {mean (2) }}\right)-\overline{\left.\Delta N^{\text {mean }}\right)^{2}}\right.}{q-1}}$

where $\overline{\Delta N^{\text {mean(1) }}}, \overline{\Delta N^{\text {mean(2) }}}$ are average values of $\Delta N^{\text {mean(1) }}, \Delta N^{\text {mean(2) }}$, respectively, $q$ is the number of observations in the sample, and $\overline{\Delta N^{\text {mean }}}$ presents the average of the differences between $\Delta N^{\text {mean(1) }}$ and $\Delta N^{\text {mean(2). }}$

As a very general rule of thumb, within this study, correlation coefficients between 0 and \pm 0.3 are considered as reflecting no correlations, between \pm 0.3 and \pm 0.7 as representing weak/moderate correlations, and from \pm 0.7 to \pm 1.0 as representing strong correlations. 


\section{Results and analysis}

Figure 2 illustrates time series of $\Delta N^{(\mathrm{TTSG})}$ and $\Delta N^{(\mathrm{CSR})}$ and their mutual correlation determined with the use of Eq. (8). Statistics of differences between those temporal variations of geoid heights (cf. Eqs. (4) and (9)) are given in Table 2.
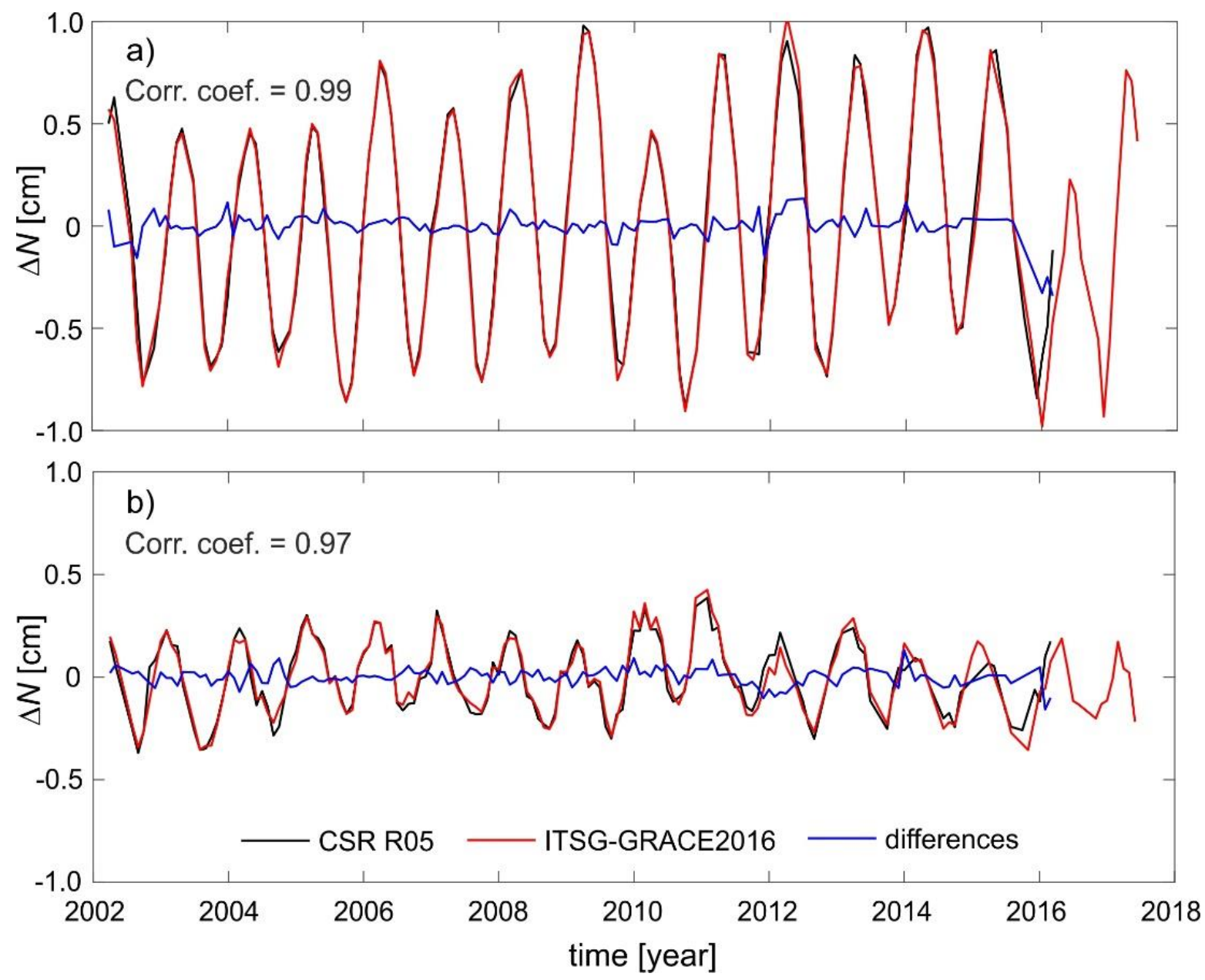

Figure 2: Time series of $\Delta N^{(\mathrm{CSR})}$ and $\Delta N^{(\mathrm{ITSG})}$ as well as their differences for

(a) the Amazon basin, and (b) the area of Poland.

Table 2: Statistics of differences between $\Delta N^{(\mathrm{CSR})}$ and $\Delta N^{(\mathrm{ITSG})}[\mathrm{mm}]$

\begin{tabular}{l|c|c|c}
\hline Study area & Min & Max & Std. dev. \\
\hline The Amazon basin & -3.4 & 1.3 & 0.6 \\
\hline The area of Poland & -1.6 & 1.3 & 0.4 \\
\hline
\end{tabular}

The results presented in Figure 2 and Table 2 indicate a very good agreement (ca. $0.5 \mathrm{~mm}$ in terms of the standard deviation of differences) between temporal variations of geoid heights 
$\Delta N^{(\mathrm{CSR})}$ over study areas obtained from GGMs developed by the CSR centre and the corresponding ones $\Delta N^{(\text {ITSG) }}$ determined from ITSG-GRACE2016 GGMs. Very strong correlations, i.e. correlation coefficients of 0.97-0.99, between $\Delta N^{(\mathrm{CSR})}$ and $\Delta N^{(\mathrm{ITSG})}$ were observed. Overall, the results presented in Figure 2 and Table 2 emphasize the suitability of the ITSG-GRACE2016 GGMs for reliable assessment of temporal variations of geoid heights for both selected study areas.

Time series of $\Delta N^{\text {(SST-hl) }}$ and $\Delta N^{(\mathrm{ITSG})}$ are shown in Figure 3. The amplitudes of $\Delta N^{(\mathrm{SST} \text {-hl) }}$ from Jason and MetOp satellite missions are considerably large; differences between maximum and minimum values of $\Delta N^{\text {(SST-hl) }}$ over Amazon basin exceed $2 \mathrm{~m}$. Thus, those time series are not shown in Figure 3. Among $\Delta N^{(\text {SST-hl) }}$ time series depicted in Figure 3, those computed from the Kompsat-5 data have noticeably larger amplitudes compared to $\Delta N^{\text {(ITSG-GRACE2016) }}$. Figure 3 also illustrates that $\Delta N^{\text {(SST-hl) }}$ obtained over the area of Poland are more noisy compared to the corresponding ones obtained over the Amazon basin. Moreover, it seems that for the area of Poland $\Delta N^{(\mathrm{SST}-\mathrm{hl})}$ time series do not follow the seasonal pattern of $\Delta N^{(\mathrm{ITSG})}$ time series.

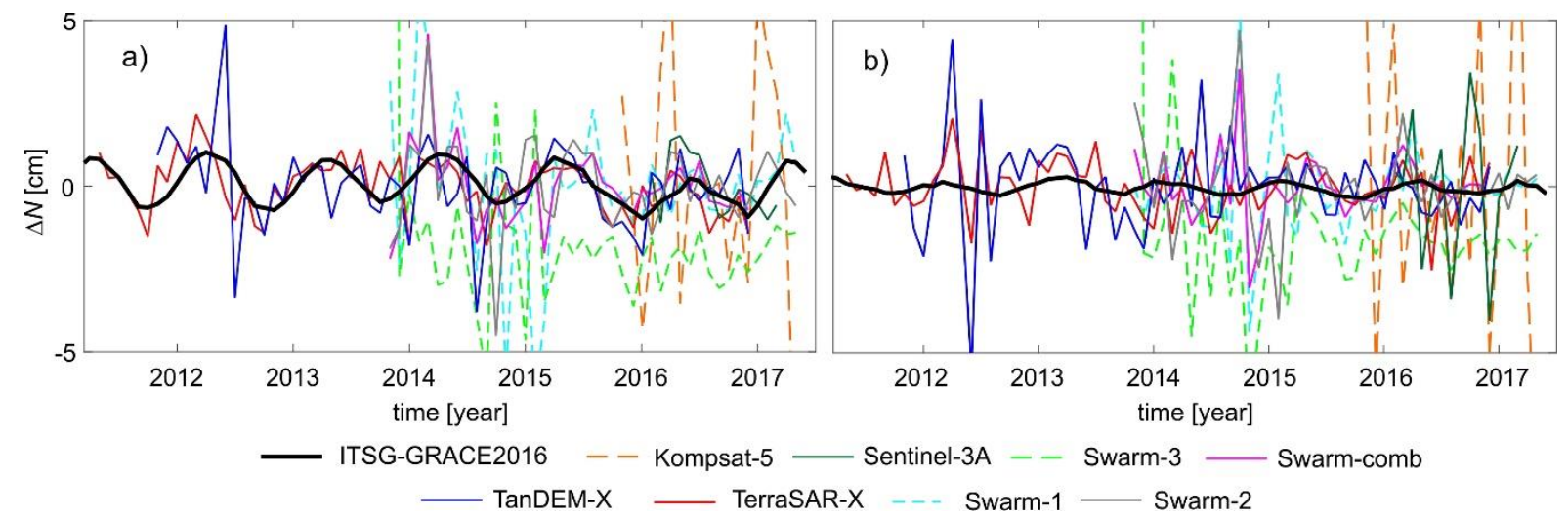

Figure 3: Time series of $\Delta N^{(\text {SST-hl) }}$ as well as $\Delta N^{(\mathrm{ITSG})}$ for (a) the Amazon basin and (b) the area of Poland.

Statistics of the differences $\delta \Delta N^{\text {(ITSG-SST) }}$ obtained using Eqs. (5) and (9) are given in Table 3. The coefficients of correlation between time series of $\Delta N^{\text {(TTSG-SST) }}$ and $\Delta N^{\text {(SST-hl) }}$ obtained with the use of Eq. (8) are shown in Figure 4. 
Table 3: Statistics of differences $\delta \Delta N^{(\mathrm{ITSG}-\mathrm{SST})}$ between $\Delta N^{(\mathrm{ITSG})}$ and $\Delta N^{(\mathrm{SST}-\mathrm{hl})}[\mathrm{mm}]$

\begin{tabular}{l|r|r|r|r|r|r}
\hline \multirow{2}{*}{$\begin{array}{l}\text { Satellite of N-DGSM providing data } \\
\text { for GGM }\end{array}$} & \multicolumn{3}{|c|}{ The Amazon basin } & \multicolumn{3}{c}{ The area of Poland } \\
\cline { 2 - 7 } & Min & Max & Std. dev. & Min & Max & Std. dev. \\
\hline Jason-2 & -346.8 & 353.0 & 160.6 & -821.8 & 614.2 & 268.9 \\
\hline Jason-3 & -144.7 & 137.0 & 86.3 & -285.6 & 290.5 & 194.5 \\
\hline MetOp-A & -283.3 & 258.7 & 120.5 & -465.4 & 662.8 & 249.3 \\
\hline MetOp-B & -298.8 & 442.8 & 142.8 & -713.3 & 437.5 & 257.7 \\
\hline Sentinel-3A & -12.4 & 13.4 & 8.4 & -34.3 & 22.7 & 19.3 \\
\hline Kompsat-5 & -108.7 & 66.6 & 41.5 & -97.2 & 107.4 & 52.5 \\
\hline Swarm-3 & -34.3 & 50.9 & 17.2 & -50.7 & 53.9 & 16.7 \\
\hline Swarm-Comb & -26.0 & 37.7 & 12.1 & -30.1 & 37.0 & 11.2 \\
(i.e. Swarm 1+2+3) & -39.1 & 41.0 & 13.5 & -55.2 & 43.3 & 15.4 \\
\hline TanDEM-X & -19.1 & 13.0 & 6.9 & -26.0 & 19.5 & 8.5 \\
\hline TerraSAR-X & -62.5 & 36.7 & 21.9 & -43.4 & 57.9 & 16.0 \\
\hline Swarm-1 & -39.7 & 36.6 & 13.4 & -42.1 & 48.8 & 15.1 \\
\hline Swarm-2 & & & & & \\
\hline
\end{tabular}

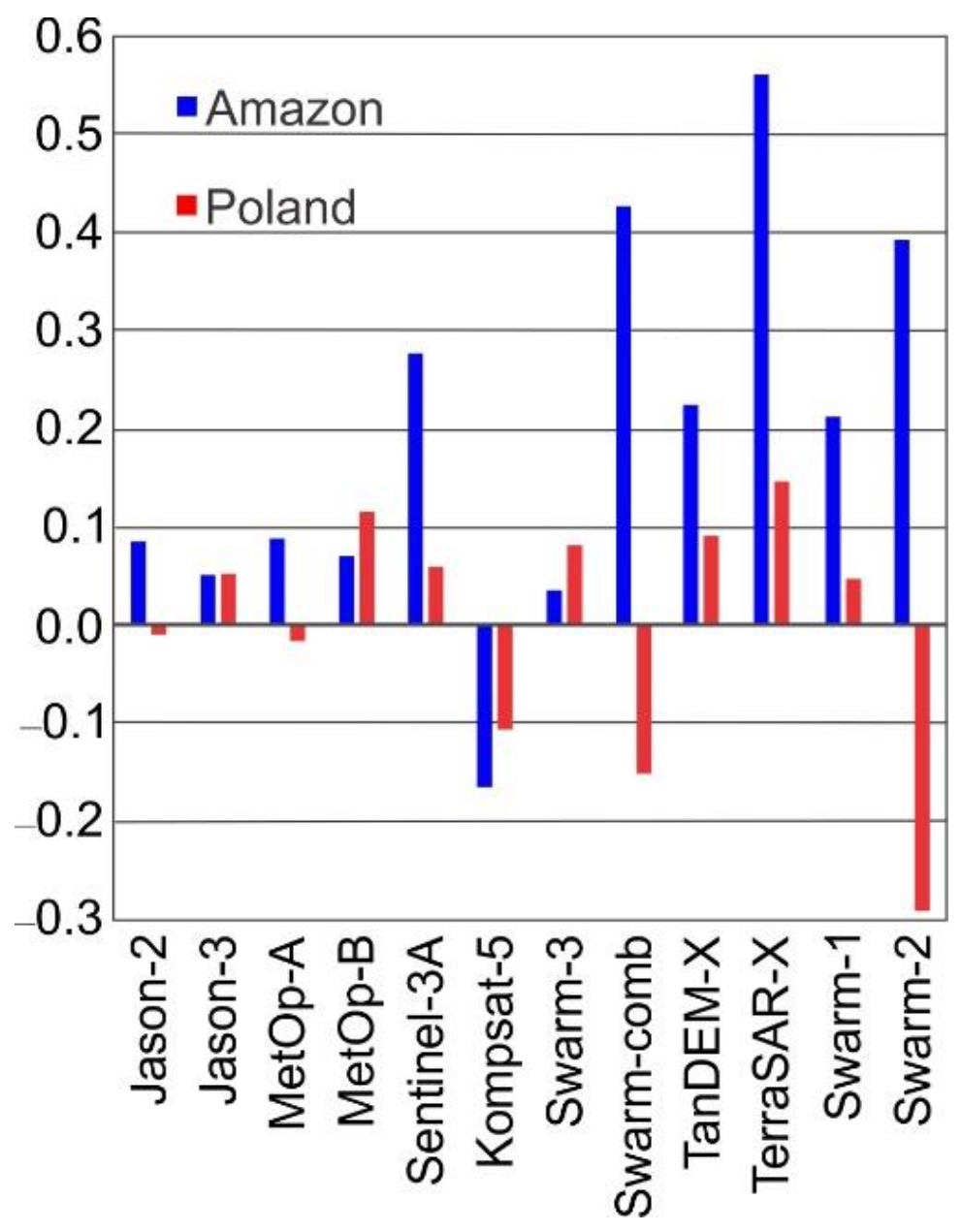

Figure 4: Coefficients of correlation between monthly mean of temporal variations of geoid heights $\Delta N^{\text {(SST-hl) }}$ determined from N-DGSM-based GGMs and the corresponding ones $\Delta N^{(\text {ITSG })}$ obtained from ITSG-GRACE2016 GGMs 
The results presented in Table 3 indicate that GGMs based on SST-hI data of Jason, MetOp and Kompsat-5 satellite missions (satellite altitudes of $550 \mathrm{~km}$ and higher) are completely inappropriate for the determination of temporal variations of geoid heights. The $\delta \Delta N^{\text {(ITSG-SST) }}$ obtained from GGMs based on those satellite missions data exceed $4 \mathrm{~cm}$ which is far out of the range of temporal variations of geoid heights (i.e. $\pm 1 \mathrm{~cm}$ from $\Delta N^{(\mathrm{ITSG})}$; cf. Fig. 2) over study areas. The Sentinel-3A is the only exception among high altitude satellites that reveal a good agreement in terms of the standard deviation of $\delta \Delta N^{(\text {ITSG-SST) }}$, i.e. $0.8 \mathrm{~cm}$ and $1.9 \mathrm{~cm}$ for the Amazon basin and the area of Poland, respectively. However, it should be noted that the currently available time series of GGMs developed using Sentinel-3A SST-hl data is very short (11 months), which is insufficient to assess the suitability of Sentinel-3A SST-hl data for the determination of temporal variations of geoid heights. For the remaining N-DGSMs investigated, standard deviations of $\delta \Delta N^{(\text {ITSG-SST) }}$ do not exceed $2.2 \mathrm{~cm}$ for the Amazon basin as well as for the area of Poland. The best agreements in terms of standard deviations of $\delta \Delta N^{\text {(ITSG-SST) }}$ of $0.7 \mathrm{~cm}$ for the Amazon basin and $0.8 \mathrm{~cm}$ for the area of Poland are obtained in the case of the TerraSAR$X$ satellite mission.

The results illustrated in Figure 4 reveal that over the Amazon basin, coefficients of correlation between $\Delta N^{(\mathrm{SST}-\mathrm{hl})}$ and $\Delta N^{(\mathrm{ITSG})}$ range from 0.39 to 0.56 for $\Delta N^{(\mathrm{SST}-\mathrm{hl})}$ obtained from GGMs based on Swarm-combined, TerraSAR-X and Swarm-2 data. For the remaining N-DGSMs, these correlation coefficients do not exceed the range of \pm 0.39 over the Amazon basin. For the area of Poland, coefficients of correlation between $\Delta N^{(\mathrm{SST}-\mathrm{hl})}$ and $\Delta N^{(\mathrm{ITSG})}$ obtained from all N-DGSMbased GGMs investigated are within the range of \pm 0.30 for $\Delta N^{(\text {SST-hl) }}$. Thus, it could merely be concluded that a week/moderate correlation between $\Delta N^{(\mathrm{SST}-\mathrm{hl})}$ and $\Delta N^{(\mathrm{ITSG})}$ can be obtained from GGMs developed on the basis of Swarm-combined, and TerraSAR-X and Swarm-2 data over the Amazon basin. For GGMs based on Jason, MetOp, Kompsat-5, Sentinel-3A, TanDEM-X, Swarm-1 and Swarm-2 satellite missions over the Amazon basin as well as for all N-DGSM-based GGMs investigated over the area of Poland, no correlations between $\Delta N^{(\text {SST-hl) }}$ and $\Delta N^{(\text {ITSG })}$ are observed.

In general, several factors might diminish the quality of $\Delta N^{\text {(SST-hl) }}$ determined from N-DGSMbased GGMs. First of all at higher altitudes, i.e. 550-1336 km (cf. Table 1), the signal reflecting variations of geoid heights is very weak and noisy. Moreover, the quality of $\Delta N^{\text {(SST-hl) }}$ depends on the strength of the signal. For areas with relatively slight temporal variations of geoid height even at lower altitudes, i.e. 450-550 km, the signal can be very noisy. The quality of GNSS observations in SST-hl technique might also be inadequate to sense that signal. Furthermore, the lack of star trackers on board of the satellite (Zehentner et al. 2014) might degrade the quality of mission results. It should be noted that GPS receivers (GPSR) mounted on Swarm and TerraSAR-X satellites are simultaneously tracking maximum 8 and 12 GPS satellites, respectively (Zehentner and Mayer-Gürr 2016). The TanDEM-X mission is based on the TerraSAR-X mission (Schulze et al. 2010). Thus, the orbit accuracy of the TerraSAR-X satellite can be higher than the corresponding ones of Swarm and TanDEM-X satellites. So that $\Delta N^{\text {(SST-hl) }}$ obtained from GGMs based on TerraSAR-X are more accurate than the ones of TanDEM-X and Swarm satellites. Despite the fact 
that Swarm-1 and Swarm-2 satellites are at the same altitude, $\Delta N^{(\text {SST-hl) }}$ from GGMs based on Swarm-2 data seem more accurate. This might be ascribed to the quality of GNSS data collected by the GPSR of Swarm-2 satellite which is better than the corresponding one of Swarm-1 satellite (e.g. van den ljssel et al. 2016).

Time series of $\Delta N^{(\text {SST-hl) }}$ of relatively slight standard deviations of $\delta \Delta N^{(\text {ITSG-SST) }}$, i.e. not exceeding $2.2 \mathrm{~cm}$, were smoothed using Eq. 6. Figure 5 illustrates time series of smoothed temporal variations of geoid heights $\Delta N^{\text {(SST-hl smoothed) }}$ and $\Delta N^{(\text {ITSG) }}$. Statistics of differences $\delta \Delta N^{\text {(smoothed) }}$ obtained with the use of Eqs. (7) and (9) are given in Table 4. Figure 6 depicts coefficients of correlation between $\Delta N^{\text {(SST-hl smoothed) }}$ and $\Delta N^{(\mathrm{ITSG})}$.
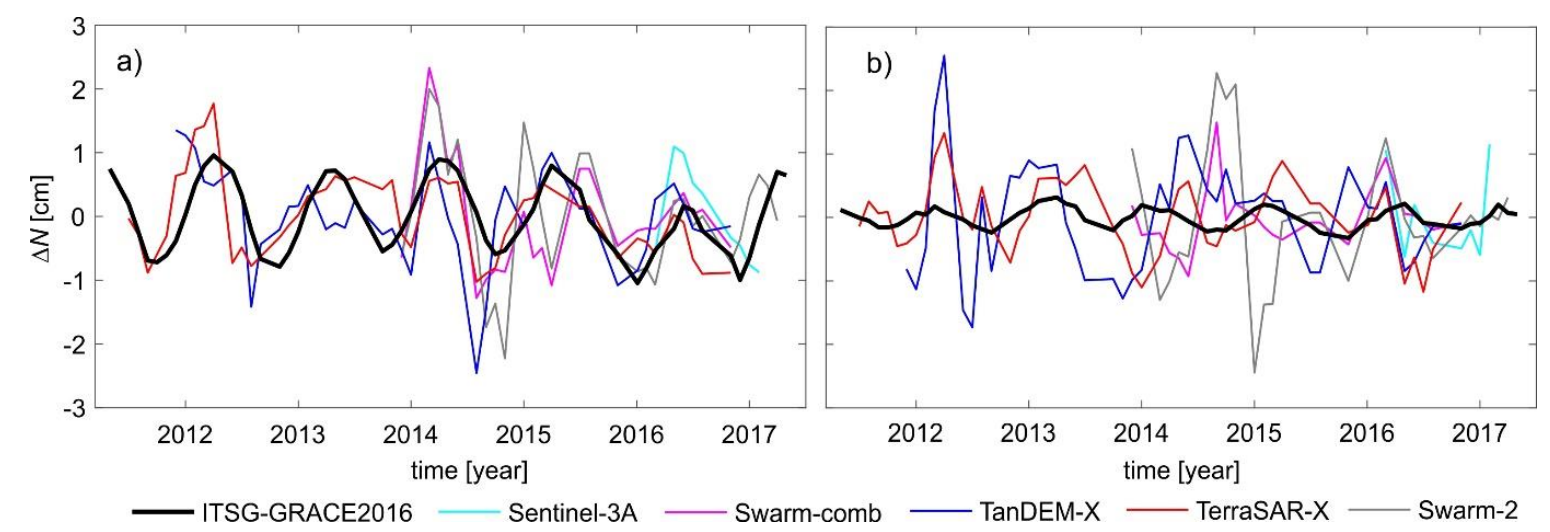

Figure 5: Time series of $\Delta N^{(\mathrm{SST}-\mathrm{hl} \text { smoothed) }}$ and $\Delta N^{(\mathrm{ITSG})}$ for (a) the Amazon basin and (b) the area of Poland.

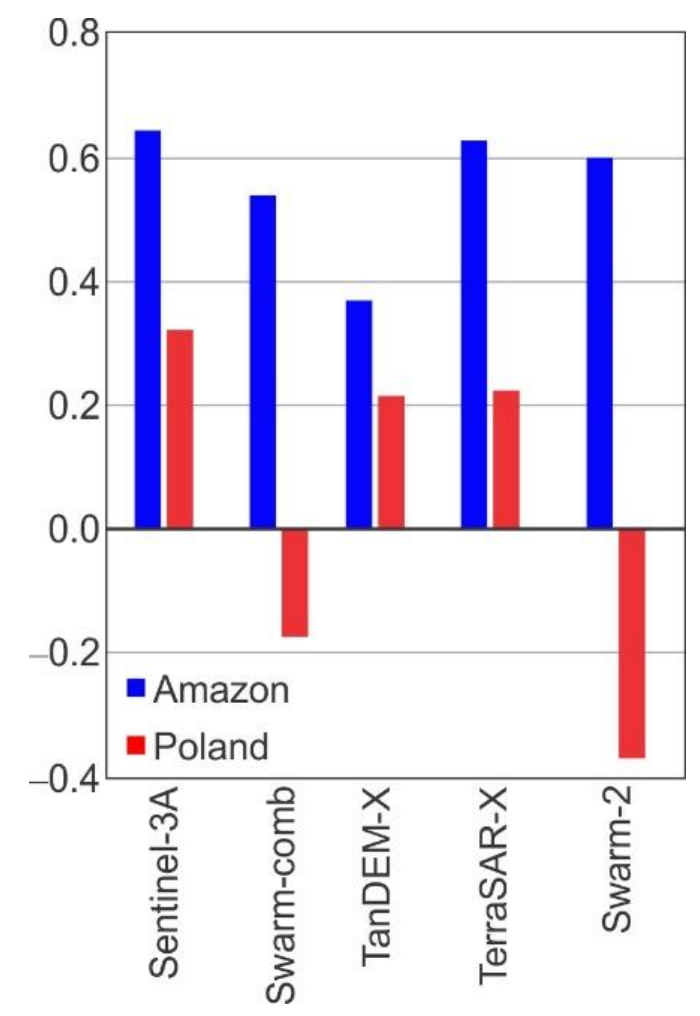

Figure 6: Coefficients of correlation between $\Delta N^{(\text {SST-hl smoothed })}$ and $\Delta N^{(\text {ITSG })}$. 
Table 4: Statistics of differences between $\Delta N^{(\mathrm{SST}-\mathrm{hl} \text { smoothed) }}$ and $\Delta N^{(\mathrm{ITSG})}[\mathrm{mm}]$

\begin{tabular}{l|l|r|r|c}
\hline \multirow{2}{*}{ Study area } & $\begin{array}{l}\text { Satellite of N-DGSM } \\
\text { providing data for GGM }\end{array}$ & Min & Max & Std. dev. \\
\hline \multirow{4}{*}{ The Amazon basin } & Sentinel-3A & -10.9 & 9.5 & 5.9 \\
\cline { 2 - 5 } & Swarm-comb & -18.9 & 15.7 & 7.4 \\
\cline { 2 - 5 } & TanDEM-X & -24.8 & 17.7 & 7.5 \\
\cline { 2 - 5 } & TerraSAR-X & -14.5 & 10.1 & 5.3 \\
\cline { 2 - 5 } & Swarm-2 & -17.4 & 15.6 & 8.0 \\
\hline \multirow{4}{*}{ The area of Poland } & Sentinel-3A & -8.6 & 11.2 & 6.5 \\
\cline { 2 - 5 } & Swarm-comb & -8.8 & 16.7 & 5.5 \\
\cline { 2 - 5 } & TanDEM-X & -16.0 & 24.7 & 8.8 \\
\cline { 2 - 5 } & TerraSAR-X & -13.0 & 12.4 & 5.4 \\
\cline { 2 - 5 } & Swarm-2 & -25.9 & 24.6 & 11.2 \\
\hline
\end{tabular}

The results presented in Figure 5 and Table 4 reveal that the fit of $\Delta N^{\text {(SST-hl smoothed) }}$ time series to $\Delta N^{(\mathrm{ITSG})}$ is remarkably better compared to the to the fit of unsmoothed, i.e. $\Delta N^{\text {(SST-hl) }}$, time series to $\Delta N^{\text {(ITSG) }}$ (cf. Fig. 3). The standard deviations of $\delta \Delta N^{\text {(smoothed) }}$ are within the range of $0.5-$ $0.8 \mathrm{~cm}$ and $0.5-1.1 \mathrm{~cm}$ for the Amazon basin and the area of Poland, respectively. Taking into the consideration statistics presented in Table 3, a clear reduction, i.e. up to 66\% for the Amazon basin and up to $44 \%$ for Poland, in terms of standard deviations of $\delta \Delta N^{\text {(smoothed) }}$ in relation to standard deviations $\delta \Delta N^{(\text {ITSG-SST) }}$ is observed. However, it should be noted that for the area of Poland standard deviations of $\delta \Delta N^{\text {(smoothed) }}$ are still large compared to the range of $\Delta N^{(\text {ITSG) }}$, i.e. ca. $0.6 \mathrm{~cm}$. The results presented in Figure 6 indicate that for the Amazon basin, coefficients of correlation between $\Delta N^{(\mathrm{SST}-\mathrm{hl} \text { smoothed) }}$ and $\Delta N^{(\mathrm{ITSG})}$ are at the level of 0.60 for Sentinel-3A, Swarm-comb, TerraSAR-X and Swarm-2 satellite missions. Figure 6 also shows that for the area of Poland, there is no correlation between $\Delta N^{\text {(SST-hl smoothed) }}$ and $\Delta N^{(\mathrm{ITSG})}$ time series. This is because even after smoothing of $\Delta N^{\text {(SST-hl) }}$, coefficients of correlation between $\Delta N^{\text {(SST-hl smoothed) }}$ and $\Delta N^{(\text {ITSG })}$ for the area of Poland are still within the range of \pm 0.37 . Moreover, Figure 5 confirms that for the area of Poland, $\Delta N^{\text {(SST-hl smoothed) }}$ time series do not follow the $\Delta N^{(\text {ITSG) }}$ pattern. The amplitudes of $\Delta N^{\text {(SST-hl smoothed) }}$ for this area are still several times larger than the amplitudes of $\Delta N^{(\text {ITSG) }}$. This may imply that N-DGSM-based GGMs investigated within this study are unsuitable for the determination of temporal variations of geoid heights for areas characterized with relatively slight temporal mass variations as for the area of Poland.

\section{Summary and conclusions}

The suitability of GGMs developed with the use of SST-hl data from non-dedicated gravity satellite missions (N-DGSM) for recovering temporal variations of geoid heights $\Delta N$ and filling the gap between GRACE and GRACE-FO was investigated at two test areas, i.e. the Amazon basin 
and the area of Poland, characterized with substantially different amplitudes of seasonal variations of geoid heights.

The $\Delta N$ obtained from ITSG-GRACE2016 GGMs, that cover the period April 2002-June 2017, were validated with the respective ones obtained from CSR RL05 GGMs. The results of this validation reveal the reliability of ITSG-GRACE2016 GGMs for the determination of $\Delta N$ over study areas.

The comparison of $\Delta N$ determined from GGMs based on SST-hl data from N-DGSMs with the corresponding ones from ITSG-GRACE2016 GGMs indicates that GGMs developed using SST-hl data from Jason-2, Jason-3, MetOp-A, MetOp-B, Kompsat-5 and Swarm-1, Swarm-3 satellites are unsuitable for the determination of $\Delta N$. In the case of the Amazon basin, week/moderate correlations (correlation coefficients from 0.39 to 0.56 ) between $\Delta N$ obtained from ITSGGRACE2016 GGMs and the corresponding ones from GGMs based on SST-hl data from Swarmcomb, TerraSAR-X and Swarm-2 satellites are observed. For the area of Poland, there is no correlation between $\Delta N$ time series based on GGMs determined from SST-hl data and the corresponding ones obtained from ITSG-GRACE2016 GGMs.

The moving average of window size of 3 months was applied to smooth $\Delta N$ time series obtained from GGMs based on SST-hl data from Sentinel-3A, Swarm-comb, TanDEM-X, TerraSAR-X and Swarm-2 satellites. The fit, in terms of standard deviations of the differences of those $\Delta N$ smoothed to the ones determined from ITSG-GRACE2016 GGMs do not exceed $8 \mathrm{~mm}$ for the Amazon basin and $12 \mathrm{~mm}$ for the area of Poland. Moderate correlation (correlation coefficients from ca. 0.55 to 0.64 ) between $\Delta N$ from ITSG-GRACE2016 and the corresponding smoothed $\Delta N$ from GGMs based on SST-hl data from Sentinel-3A, Swarm-comb, TerraSAR-X and Swarm-2 satellites was obtained for the Amazon basin. There is no correlation between $\Delta N$ time series obtained from these N-DGSM-based GGMs and the corresponding ones from ITSG-GRACE2016 GGMs over the area of Poland. The seasonal pattern even in smoothed $\Delta N$ time series obtained from GGMs developed on the basis of SST-hl data from N-DGSMs is invisible for the area of Poland, although standard deviations of differences between smoothed $\Delta N$ and the ones from ITSG-GRACE2016 GGMs for this area are at the similar level, i.e. 0.5-1.0 cm, as for the Amazon basin. The cause for such results is the strength of $\Delta N$ signal investigated, which is much stronger for the Amazon basin than for the area of Poland. Thus, the reliability of SST-hI data for the determination of temporal variations of geoid heights strongly depends on the magnitude of the mass transport, which is related to the geographical location.

Over the Amazon basin, $\Delta N$ obtained from N-DGSM-based GGMs indicate that the quality of GGMs developed on the basis of SST-hl data from the TerraSAR-X satellite mission is superior with respect to those developed on the basis of SST-hl from other N-DGSMs. To some extent, GGMs developed on the basis of SST-hl data from TanDEM-X, Swarm-comb, Swarm-2 and Sentinel-3A N-DGSMs seem suitable to provide valuable information concerning $\Delta N$ for the Amazon basin. Overall, in the gap between GRACE and GRACE Follow-On, temporal variations of geoid heights might be determined from GGMs based on SST-hl data from N-DGSM for areas characterized with strong mass transport such as the Amazon basin. For the determination of $\Delta N$ 
over areas with similar mass transport as the area of Poland, GGMs based on SST-hl data from the N-DGSMs investigated seem not able to recover these variations. For areas where these variations are smaller than for the Amazon basin but greater than for the area of Poland further investigations are needed even for the missions taken into consideration within this study.

\section{ACKNOWLEDGEMENT}

This work was supported by the Polish National Science Centre (NCN) within the research Grant No. 2017/26/D/ST10/00422.

\section{AUTHOR'S CONTRIBUTION}

Conceptualization, W.G., M.S. and J.K.; Data Acquisition, M.S. and W.G.; Methodology, W.G. and M.S.; Software, W.G.; Results Analysis, W.G. and M.S.; Visualization, W.G. and M.S.; Writing Original Draft Preparation, W.G.; Writing - Review \& Editing, W.G., M.S. and J.K.; Supervision, J.K.; Funding Acquisition, W.G. M.S. and J.K.

\section{REFERENCES}

Bettadpur, S. 2012. UTCSR Level-2 Processing Standards Document for Level-2 Product Release 0005. GRACE 327-742, CSR Publ. GR-12-xx, Rev. 4.0, University of Texas at Austin, 16pp.

Bezděk, A. Sebera, J. Encarnação, J. and Klokocnik, J. 2016. Time-variable gravity fields derived from GPS tracking of Swarm. Geophysical Journal International, 205, pp.1665-1669. DOI: 10.1093/gji/ggw094.

Cheng, M.K. Tapley, B.D. and Ries, J.C. 2013. Deceleration in the Earth's oblateness. Journal of Geophysical Research, 118, pp.1-8.

da Encarnação, J.T. et al. 2016. Gravity field models derived from Swarm GPS data. Earth, Planets and Space, 68, pp.127. DOI: 10.1186/s40623-016-0499-9.

Dahle, C. et al. 2017. Using Swarm for gravity field determination - an overview after 3+ years in orbit. Fourth Swarm Science Meeting, Banff, Alberta, Canada, March 20-24, 2017.

DLR, 2009. TanDEM-X Die Erde in drei Dimensionen. Köln: Deutsches Zentrum für Luft- und Raumfahrt. [online] (updated May 2019) Available at: <https://www.dlr.de/dlr/en/desktopdefault.aspx/tabid-10378/566_read-426/\#/gallery/345> Accessed 18 June 2019.

Drewes, H. Kuglitsch, F. Adám, J. and Rózsa, S. 2016. The Geodesist's handbook 2016. Journal of Geodesy, 90(10), pp.907-1205. DOI: 10.1007/s00190-016-0948-z.

Floberghagen, R. et al. 2011. Mission design, operation and exploitation of the gravity field and steady-state ocean circulation explorer mission. Journal of Geodynamics, 85(11), pp.749-758. DOI: 10.1007/s00190-011-0498-3. 
Friis-Christensen, E. Lühr, H. Knudsen, D. and Haagmans, R. 2008. Swarm - An Earth Observation Mission investigating Geospace. Advances in Space Research, 41(1), pp.210-216.

Godah, W. 2019. IGiK-TVGMF: A MATLAB package for computing and analysing temporal variations of gravity/mass functionals from GRACE satellite based global geopotential models. Computers \& Geosciences, 123, pp.47-58.

Godah, W. Szelachowska, M. and Krynski, J. 2017. On the analysis of temporal geoid height variations obtained from GRACE-based GGMs over the area of Poland. Acta Geophysica, 65(4), pp.713-725.

Godah, W. Szelachowska, M. and Krynski, J. 2018. Application of the PCA/EOF method for the analysis and modelling of temporal variations of geoid heights over Poland. Acta Geodaetica et Geophysica, 53(1), pp.93-105.

GRACE-FO, 2018. Gravity Recovery and Climate Experiment Follow-On. [online] Available at: $<$ https://gracefo.jpl.nasa.gov/> [Accessed 1 October 2018].

GSTM, 2018. GRACE/GRACE-FO Science Team Meeting 2018. [online] Available at: <https://meetingorganizer.copernicus.org/GSTM-2018/meetingprogramme> [Accessed 29 December 2018].

Jäggi, A. et al. 2018. Assessment of individual and combined gravity field solutions from Swarm GPS data and mitigation of systematic errors. European Geosciences Union (EGU) General Assembly, Vienna, Austria, 8-13 April; Geophysical Research Abstracts, Vol. 20, EGU2018-8944.

Jason-3, 2018. Jason-3. Available at: <https://www.nesdis.noaa.gov/jason-3/> [Accessed 1 October 2018].

Krynski, J. Kloch-Główka, G. and Szelachowska, M. 2014. Analysis of time variations of the gravity field over Europe obtained from GRACE data in terms of geoid height and mass variations. In: Rizos, C. Willis, P. (eds). Earth on the Edge: Science for a Sustainable Planet. International Association of Geodesy Symposia 139: 365-370. Doi: 10.1007/978-3-642-37222-3_48.

Lück, C. Kusche, J. Rietbroek, R. and Löcher, A. 2018. Time-variable gravity fields and ocean mass change from 37 months of kinematic Swarm orbits. Solid Earth, 9, pp.323-339. DOI: 10.5194/se9-323-2018.

Mayer-Gürr, T. et al. 2016. ITSG-Grace2016 - Monthly and Daily Gravity Field Solutions from GRACE. GFZ Data Services. DOI: icgem.2016.007.

METOP, 2018. METOP. Available at: <http://www.esa.int/esaLP/SEM95PXTVKG_LPmetop> [Accessed 1 October 2018].

Neeck, S.P. and Vaze, P.V. 2008. The Ocean Surface Topography Mission (OSTM). Proc. SPIE 7106, Sensors, Systems, and Next-Generation Satellites XII, 710603 (9 October 2008); DOI: 10.1117/12.803677; https://doi.org/10.1117/12.803677.

Pavlis, N.K. Holmes, S.A. Kenyon, S.C. and Factor, J.K. 2012. The development and evaluation of the Earth gravitational model 2008 (EGM2008). Journal of Geophysical Research: Solid Earth, 117, pp.B04406.

Rangelova, E. 2007. A dynamic geoid model for Canada. PhD. Thesis, University of Calgary, Department of Geomatics Engineering, Report No. 20261. 
Rangelova, E. Fotopoulos, G. and Sideris, M.G. 2010. Implementing a dynamic geoid as a vertical datum for orthometric heights in Canada. In: Mertikas, SPP. (ed) Gravity, geoid and earth observation. International Association of Geodesy Symposia, 135, pp.295-302.

Rangelova, E. and Sideris, M.G., 2008. Contributions of terrestrial and GRACE data to the study of the secular geoid changes in North America. Journal of Geodynamics, 46(3), pp.131-143.

Reigber, C. Lühr, H. and Schwintzer, P. 2002. CHAMP mission status. Advances in Space Research, 30(2), pp.129-134. DOI: 10.1016/S0273-1177(02)00276-4.

Rothacher, M. et al. 2007. The tracking, occultation and ranging (TOR) instrument onboard TerraSAR-X and on TanDEM-X. In: International Geoscience and Remote Sensing Symposium (IGARSS). leee, pp.4983-4986. isbn: 14244 12129. DOI: 10.1109/IGARSS.2007.4423980.

Sang-Ryool, L. 2010. Overview of KOMPSAT-5 Program, Mission, and System. In: IEEE (Institute of Electrical and Electronics Engineers), IGARSS (International Geoscience and Remote Sensing Symposium). Honolulu, HI, USA, July 25-30, 2010.

Schulze, D. et al. 2010. TanDEM-X mission concept and status. Proc. 'Fringe 2009 Workshop', Frascati, Italy, 30 November - 4 December 2009 (ESA SP-677).

Sentinel, 2018. Sentinel. Available at: <https://sentinel.esa.int/web/sentinel/missions/sentinel-3> [Accessed 1 October 2018].

Tapley, B.D. et al. 2004. GRACE Measurements of Mass Variability in the Earth System. Science, 305, pp.503-506. DOI: 10.1126/science.1099192.

Torge W. and Müller J., 2012. Geodesy. $4^{\text {th }}$ edn. Walter de Gruyter, Berlin-Boston.

TVGOGO, 2018: TVGOGO. Available at: https://www.tugraz.at/institute/ifg/projects/theoreticalgeodesy-and-satellite-geodesy/tvgogo/ [Accessed 1 October 2018].

van den Ijssel, J. Forte, B. and Montenbruck, O. 2016. Impact of Swarm GPS receiver updates on POD performance. Earth, Planets and Space, 68, pp.85. DOI: 10.1186/s40623-016-0459-4.

Veis, G. 1960. Geodetic Uses of Artificial Satellites. Smithsonian Contributions to Astrophysics, 3(9), pp.95.

Wahr, J. Molenaar, M. and Bryan, F. 1998. Time variability of the Earth's gravity field: Hydrological and oceanic effects and their possible detection using GRACE. Journal of Geophysical Research, 103(B12), pp.30205-30229.

Zehentner, N. and Mayer-Gürr, T. 2016. Precise orbit determination based on raw GPS measurements. Journal of Geodesy, 90(3), pp.275-286. DOI: 10.1007/s00190-015-0872-7.

Zehentner, N. Mayer-Gürr, T. Weigelt, M. and Jäggi, A. 2014. Non-dedicated satellite missions for time variable gravity field estimation. Grace Science Team Meeting, Potsdam, 28-30 Sept. 2014. 